\title{
Infant Gastroesophageal Reflux (GER): Benign Infant Acid Reflux or just Plain Aerophagia?
}

\author{
Lawrence Kotlow ${ }^{*}$
}

\author{
Private Practice, 340 Fuller Road, Albany, NY 12203, USA
}

\begin{abstract}
Physicians are often asked to diagnose and treat infants with clinical signs of gastroesophageal reflux (GER) symptoms and in extreme cases gastroesophageal reflux disease (GERD). Some infants are left to work out their pain, regurgitation and vomiting until they outgrow the symptoms while others may undergo expensive, invasive endoscopic procedures in the operating room under general anesthesia. Initial treatment is often for infants to be placed on prescription adult acid reflux medications, which have limited benefits [1]. Drugs prescribed include: $\mathrm{H}-2$ blockers such as ranitidine (Zantac), a proton pump inhibitor such as omeprazole (Prilosec) or lansoprazole (Prevacid). TOTS may cause aerophagia, a condition where the infant's latch onto the mother's breast or bottle allows the infant to swallow excessive amounts of air into the stomach during feeding. This aerophagia may be responsible for symptoms mimicking GER or GERD [2]. When these infants are examined for symptoms of GER the differential diagnosis of tethered oral tissues (TOTS) may not be addressed [3]. Tethered oral tissues may involve ankyloglossia (tongue-tied), maxillary and /or mandibular frenum lip-ties and in some instances buccal frenum ties. These tethered oral tissues (TOTS) prevent the infant from achieving a good seal onto the breast and or bottle with the resulting ingestion of excessive amounts of air.
\end{abstract}

Background: When assessing infants presenting with gastroesophageal reflux symptoms, aerophagia secondary to tethered oral tissues (tongue-ties, Lip-ties) should be considered in the differential diagnosis since the release of these tissues may eliminate the need for invasive gastrointestinal investigations and pharmacologic treatment of gastroesophageal reflux.

Patient Pool: 340 infants ranging from 1 week to 3 months were referred for the evaluation and release of lingual and maxillary lips which were interfering with infant's ability to achieve a good seal and latch onto the mother's breast of infant bottle. The survey the parents completed indicated that 208 or $61 \%$ of the infants had signs of gastroesophageal reflux (GER) such as; vomiting, regurgitation, inability to sleep lying supine, fussiness, crying after nursing and morning congestion. Of the 208 infants $40 \%$ (83 infants) were or had been treated for GER with pharmacologic medications such as proton pump inhibitors or $\mathrm{H} 2$ blockers without any resolution of the symptoms.

Findings: All of the infants presenting with these signs and symptoms underwent laser revisions of the tethered attachments. Upon completion of the procedure and at a 48 hour post-surgical follow-up discussion with the parents $93 \%$ (194 infants) of the infants showed immediate improvements and were able to breastfeed successfully without signs or symptoms of GER. Survey returned at the end of two weeks post-surgery had similar results

Conclusion: Infants presenting with signs of GER should also be evaluated for restrictive tethered oral tissues (TOTS) such as ankyloglossia, lip and buccal ties. If they are present, strong consideration should be given to the release of these tissues as an initial approach. This may eliminate the need for pharmacologic treatment of GER.

Keywords: Breastfeeding, reflux, aerophagia, laser surgery, lip-ties, tongue-ties.

\section{INTRODUCTION}

Physicians are often required to diagnose and treat infants with clinical signs of gastroesophageal reflux (GER) and in extreme cases gastroesophageal reflux disease (GERD). Infant reflux is defined as a condition where the contents of the stomach are spit out, usually shortly after feeding. A differential diagnosis of (GER) as well as its treatment can vary. It is often recommended that the family wait it out, since reflux in many instances will become less common as an infant gets older, or if the symptoms persist the reflux may be diagnosed as gastroesophageal reflux disease (GERD). Although GER is not usually considered a pathological condition, its therapeutic management represents a controversial issue. Pharmacological treatment of GER may not resolve the issues.

*Address correspondence to this author at the Private Practice, 340 Fuller Road, Albany, NY 12203, USA; Tel: 5184892571; E-mail: kiddsteeth@aol.com
Gastroesophageal Reflux (GER) is common in preterm infants with these infants presenting with signs and symptoms of GER as high as $22 \%$. Nonpharmacological approaches such as changing infant body positions or alternative feeding strategies may reduce or eliminate the problems [4].

\section{BACKGROUND}

In a survey of 948 healthy infants up to 13 months of age, regurgitation of at least one episode was found to be evident in half of infants $0-3$ months of age, peaking to $67 \%$ at 4 months of age. Increased crying and fussiness accompanied by regurgitation, discomfort with spitting up and frequent back arching due to pain were presenting symptoms [5].

\section{JUSTIFICATION}

GER is often attributed to as an allergy or a blockage requiring surgical intervention when pyloric 
sphincter stenosis is present. Others suggest that spitting up and regurgitation are simply the usual symptoms of GER and that as long as an infant is healthy, content and growing well, the reflux and its symptoms are not a cause for concern or intervention. Comments such as your child will in all likelihood outgrow it are common.

While it may be true that symptoms of (GER) will eventually resolve as the infant gets older, advising parents to just wait it out and have their infants continue to have pain, cry, act fussy and remain uncomfortable from three to twelve months is not comforting for parents.

Infants spend a great amount time lying in a supine or semi-supine position. This allows the movement of stomach's contents to move toward the esophagus, which in turn can cause GER symptoms to become more prevalent. Infant nourishment in breastfed and bottle fed infants is usually completely liquid for the first six months of life; thus the movement of the stomach's contents upward is even more probable and can contribute to the development of infant reflux symptoms. Sometimes it is suggested that an infant might simply drink too much, too fast. Although infant reflux most often occurs after a feeding session, it can happen anytime an infant coughs, cries or strains.

\section{Differential Diagnosis}

The usual differential diagnosis for determining the causes of infant reflux include evaluation for such conditions as; allergic gastroenteritis, which is defined as an intolerance to something in food, usually a protein in cow's milk.

Gastroesophageal reflux disease (GERD) is a more severe condition where the reflux is acidic enough to actually irritate and damage the lining of the esophagus. Eosinophilic esophagitis is an allergic condition where eosinophils infiltrate the lining of the esophagus.

A search of the exiting literature indicates that in the vast majority of cases TOTS is not considered in the evaluation of infants presenting with GER When an infant is found to be swallowing large amounts of air into the stomach a condition known as aerophagia, can force the stomach's content upward which is then followed by regurgitation or even projectile vomiting of the contents.

\section{Pharmacologic Treatments}

Initial treatment of infant gastroesophageal reflux (GER) is to prescribe adult anti-reflux drugs. Infants are placed on oral medication such as; Acid-blocking drugs like an $\mathrm{H}-2$ blocker such as ranitidine (Zantac), a proton pump inhibitor such as omeprazole (Prilosec) or lansoprazole (Prevacid) [6]. Pharmacologic treatment of infants with reflux symptoms is problematic, as many infants have GER, and little correlation has been noted between symptoms and endoscopic and $\mathrm{PH}$ findings. Little evidence exists to suggest that pharmacologic agents help these infants. Children taking these medications may also face an increased risk of certain intestinal and respiratory infections. In infants, prolonged use of proton pump inhibitors has been linked to problems in iron and calcium absorption.

\section{Non-Pharmacologic Evaluation}

1. An ultrasound can be used to detect an obstruction such as pyloric stenosis in the opening between the stomach and small intestine.

2. Laboratory blood and urine tests can identify or rule out possible causes of recurring vomiting and poor weight gain.

3. Esophageal $\mathrm{pH}$ monitoring can used to determine if irritability, sleep disturbances or other symptoms are associated with reflux of stomach acid. During this procedure the acidity within an infant's esophagus is evaluated by inserting a thin tube through the infant's nose or mouth into the esophagus. The tube is then attached to a device that monitors acidity. This test may require an infant to be hospitalized during the monitoring.

4. Upper Gl series consisting of exposing a newborn infant to a series of X-rays known as an upper gastrointestinal (Gl) series. During this procedure, prior to the taking of radiographs, an infant is given barium, which is a dry, white, chalky powder that is mixed with water to make barium liquid. Barium absorbs the $x$-rays and appears white on the diagnostic film. When swallowed into the Gl tract, barium coats the inside wall of the esophagus and the stomach walls, which helps any abnormalities show up more clearly on the X-rays. 
5. The upper endoscopy is a more invasive diagnostic procedure. This consists special tube equipped with a camera lens and light placed through an infant's oral cavity into the esophagus, stomach and first part of the small intestine. If needed, a biopsy of any suspicious tissue may be taken for analysis. For infants and children, endoscopy is usually completed under general anesthesia.

Present studies have suggested that infants undergoing general anesthesia may have an increase the risk for learning disabilities and a potential for the development of behavioral problems such as attention deficit hyperactivity disorder (ADHD).

At the conclusion of all these tests; infants undergoing x-ray exposure, expensive, invasive and time consuming procedures, there often remains an inability to make any type of clear diagnosis [7-12].

\section{Objectives}

Gastroesophageal reflux (GER) occurs when the stomach contents flow back up into the esophagus of infants and this often results in repeated episodes of projectile vomiting or regurgitation of the stomach's contents immediately after nursing. The involvement of ankyloglossia (tongue-tie) and upper lip -ties (TOTS) should be part of the differential diagnosis. Revising tethered oral tissues eliminates the need for and pharmacologic intervention, radiation, general anesthesia, hospitalization, blood tests, or other invasive procedure.

\section{PATIENT SUBJECTS AND METHODS USED}

Within the author's private pediatric dental practice, a group of 340 mothers who were referred to the practice due to breastfeeding difficulties and having infants ranging from 1 week to 8 months of age were asked to respond to presurgery breastfeeding questioner. The mothers indicated that in 194 of the infants there were symptoms related to a diagnosis of gastroesophageal reflux such as; vomiting, regurgitation of milk, pain, and excessive gas after nursing as well as nasal congestion in the morning. An oral clinical examination by the author and careful observation of the infants attempting to breastfeed indicated a shallow latch and a history of clicking and sucking in air while attempting to latch onto the mother's breast or similarly when attempting to latch onto a bottle. Of these 194 infants over $40 \%$ were being treated by their physicians with various types of anti-reflux drugs with no apparent resolution of symptoms of GER from a few days to as long as a few months.

The authors clinical examination indicated that the existence of tethered oral tissues were likely the primary causative factor. The releases of these tissues (the tongue and upper lip) were surgically completed in the dental office. The post-surgical follow-up at 48 hours indicated that $93 \%$ of the infants the release of the upper lip and tongue-ties showed immediate improvement in clinical signs of gastrointestinal reflux such as; regurgitation or vomiting after nursing, pain, arching of back, sleep and morning nasal congestion. A post-surgery survey returned at two weeks indicated that there were no relapses and the infants remained symptom free.

Examination of older children who had not had the areas revised and were examined as new patients over the age of 12 months, and who were treated pharmacologically without significant improvement, had histories of problems with swallowing and chewing with the introduction of solid foods and thus diets were limited to pureed foods. The tethered tongue prevents effective food movements around the mouth for chewing and swallowing. Release of the tongue aids in the elimination of these problems and children begin to eat and chew normally.

\section{DISCUSSION} 18].

Dentistry, infants and Tethered Oral Tissues [13-

\section{Pre Surgical Infant History Forms: Form A}

\section{Infant Symptom History}

1. Vomiting after breastfeeding (also may occur with bottle feeding).

2. The infant is unable to sleep while lying down.

3. Constant irritability and crying unless held upright.

4. Can only be comforted when sleeping in a parent's arms, infant car seat or swing.

5. The Infant wakes up congested in the morning, sometimes leading to treating the problem as an allergy to mother's milk. 
6. A physical history exam by the parents after nursing indicates the infant having a distended or hard belly after breastfeeding.

7. A history of being very gassy.

8. Evaluation of the mother's latch shows that the attachment to the mother's breast is weak, inconsistent, and poor and is associated with clicking or sucking in air into the stomach known as aerophasia. Aerophagia is a condition of excessive air swallowing, which goes to the stomach.

9. Infants may have slow weight gain or a diagnosis of failure to thrive.

\section{Typical Results after Treatment}

The following photos are from an 8.5-month-old infant who underwent all of the medical differential diagnostic procedures as well as genetic testing as well as having the parents be told the infant might have severe developmental problems. Revision of the lip and tongue resolved these problems.

\section{Clinical Examination Revealed the Following}

This infant was seen at age 8 months of age and had the above listed symptoms during the first 8 months. The breastfeeding history included all of the prior symptoms. Delayed growth both physically and neurologically, use of variety of different pharmacologic medications, hospitalizations, and tests to rule out Crohn's disease, Celiac disease, genetic abnormalities. Clinical evaluation of the lingual and maxillary lip ties indicated they were significantly tethered.

Post-surgical results as reported by the infant's mother:

The infant immediately latched the evening after revision; symptoms slowly resolved and by 12 months of age both physically and neurologically were normal

Photo A: Preoperative photo of maxillary lip-tie. The presurgical appearance of the maxillary lip-tie indicated the existence of a wide diastema due to a thick, fibrous frenum attachment. The attachment interfered with the upper lip from flanging upward thus causing a shallow latch and preventing the infant from achieving a tight latch.

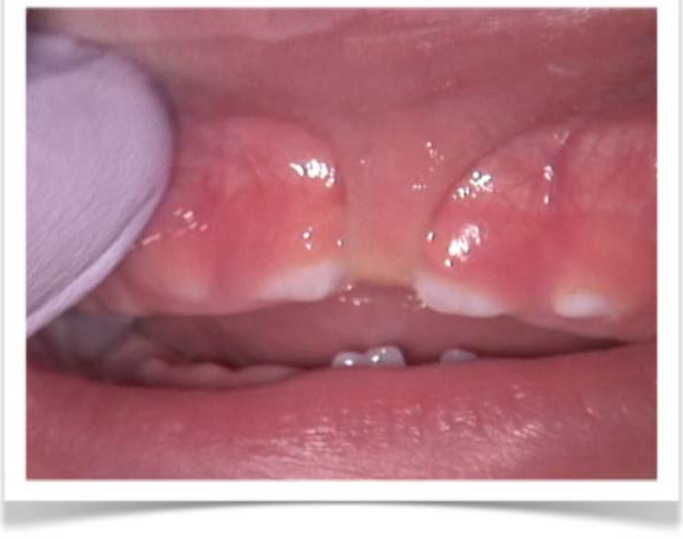

\section{Photo A:}

Photo B: The presurgical appearance of the infant's tongue attachment to the floor of the mouth indicated the tongue was unable to extend forward, upward or laterally, thus limiting the tongue's ability to express milk efficiently from the mother's breast.

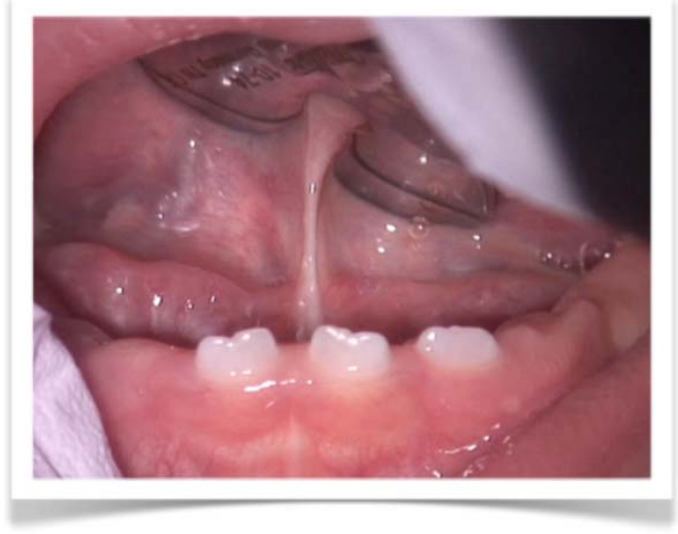

\section{Photo B:}

Photo C: A photo of the infant after attempting to breastfeed shows the infant's belly distended with air due to the shallow latch and ingestion of air (aerophagia).

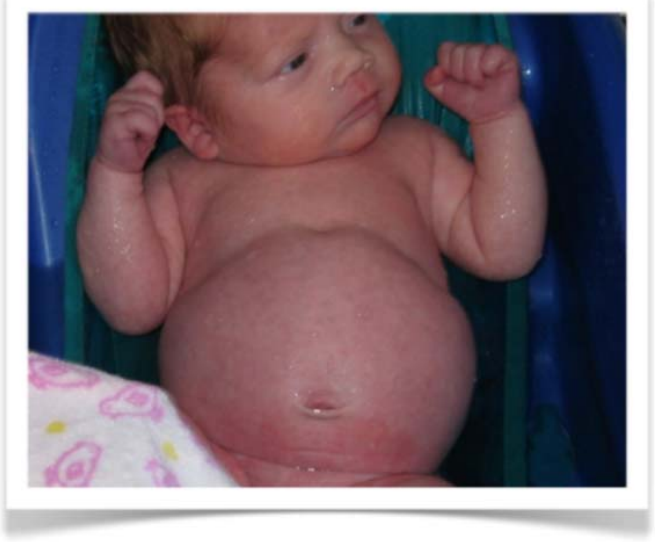

Photo C: 


\section{CONCLUSION}

An infant achieves a good latch onto the mother's breast when the upper lip adequately flanges upward and the untethered tongue easily slides under the nipple allowing the infant to attach comfortably and tightly to the areola, not nipple. This latch allows for the creation of a vacuum to express mother's milk painlessly and efficiently. When evaluating the infant's latch indicates a noisy clicking shallow attachment the results are often ingestion of large of amounts of air into his or her belly. When evaluation of tethered oral tissues as part of a differential diagnosis was not included and properly evaluated, the medical evaluation is often inconclusive.

Treatment to surgically revise these tissues can easily, safely and quickly be completed in the dental office [19]. Conventional treatments have been to use surgical scissors or electrosurgery. Although there are

\section{FORM A}

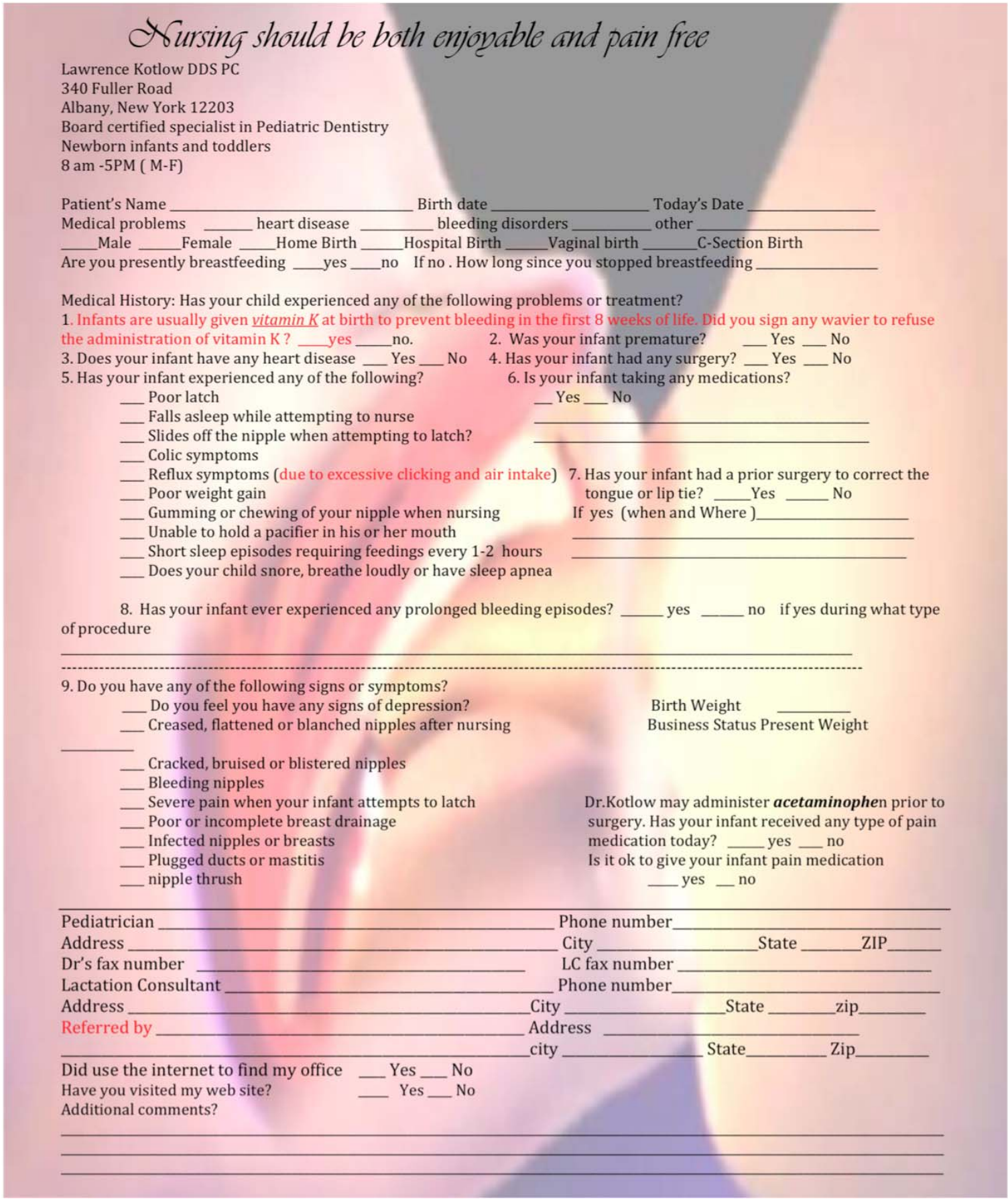


many capable providers using these techniques, today's state of the art surgical techniques involves the use of dental lasers. Surgically releasing the lip and tongue-ties requires about 20 seconds of laser energy. Dental lasers have be available since the late 1990s and have been shown to be bactericidal, show improved healing and do less collateral damage to adjacent tissue which can be experienced from the other the other surgical methods. Release of the upper lip involves elevation the lip as the laser energy ablates the tissue and therefore frees up the tethered tissue by quickly and safely vaporizing the frenum attachment. Release of the tongue-tie is completed by elevating the tongue upward exposing the restrictive frenum attachment and allowing the laser energy to ablate and free up the tongue to eliminate the restrictive tissue completely to the base of the tongue.

It is important to include tethered oral tissues such as tongue-ties and lip-ties as part of a differential diagnosis when an infant presents with signs of infant reflux. If it is found that these tissues restrict the infant

\section{FORM B}

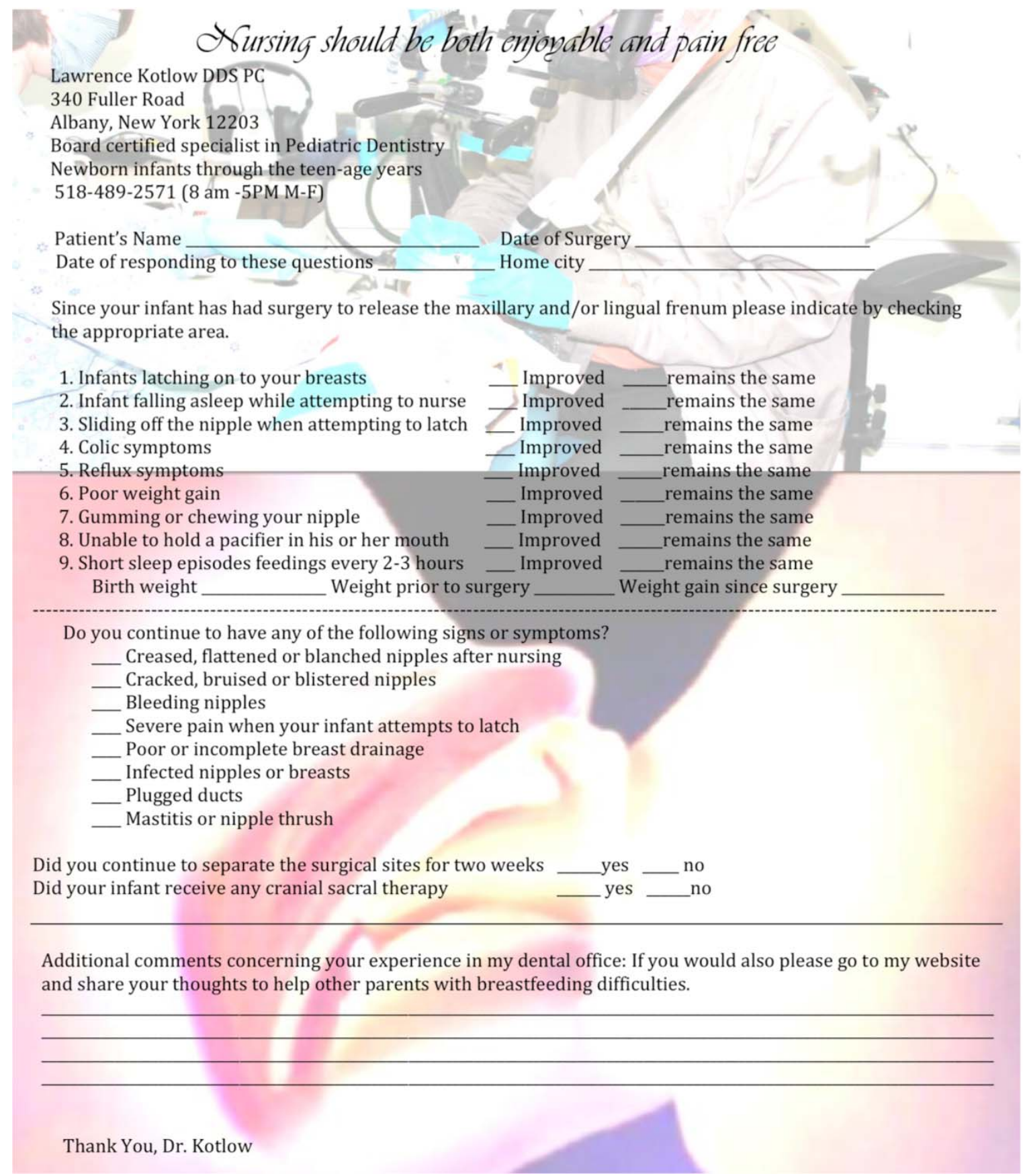


from achieving a good latch and allow for ingestion of large amounts of air into the infant's belly, the tissue should be revised before more invasive procedures are considered or using drugs to control the reflux.

\section{ETHICAL CONSIDERATIONS}

The patients were routine referred patients and required no type of ERB or permission to treat or evaluate. Parents were given informed consent through oral discussions with the author as well as viewing PowerPoint presentations as to procedures, diagnosis, treatment and post surgical care and were asked to return form $B$ in $2-3$ weeks

\section{COMPETING INTERESTS}

The author declares no competing interest.

\section{REFERENCES}

[1] Tighe M, Afzal N, Bevan A, Munro A, Beattie R. Pharmacological treatment of children with gastro esophageal reflux. Cochrane Data Base Syst Rev 2014; 24 : 11 CD008550. doi 10,1002/14651858.cCD008550 .pub

[2] Kotlow L. Infant reflux and aerophagia associated with the maxillary lip-tie and ankyloglossia. Clinical Lactation 2001; 24: 25-9.

[3] Kotlow L. TOTS-tethered oral tissues the assessment and diagnosis of the tongue and upper lip ties in breastfeeding. Journal of Oral Health 2015 March.

[4] Corvaglia L, Martini S, Aceti A, Arcuri S, Rossini R, Faldella G. Non-pharmacological management of gastroesophageal reflux in preterm infants. Biomed Res Inst 2013; 2013: 141967.

http://dx.doi.org/10.1155/2013/141967

[5] Nelson SP, Chen EH, Syniar GM, Christoffel KK. Prevalence of symptoms of gastroesophageal reflux during infancy. A pediatric practice-based survey. Pediatric Practice Research Group. Arch Pediatr Adolesc Med 1997; 151: 569-72. http://dx.doi.org/10.1001/archpedi.1997.02170430035007

[6] Vandenplas Y, Rudolph CD, Di Lorenzo C, et al. North American Society for Pediatric Gastroenterology Hepatology and Nutrition, European Society for Pediatric Gastroenterology Hepatology and Nutrition. Pediatric gastroesophageal reflux clinical practice guidelines: joint recommendations of the North American Society for Pediatric Gastroenterology, Hepatology, and Nutrition (NASPGHAN) and the European Society for Pediatric Gastroenterology,
Hepatology, and Nutrition (ESPGHAN). J Pediatr Gastroenterol Nutr 2009; 49: 498-547. doi: 10.1097/MPG.0b013e3181b7f563.

[7] Sun L. Early childhood general anaesthesia exposure and neurocognitive development. $\mathrm{Br} J$ Anaesth 2010; 105(Suppl 1): i61-8. http://dx.doi.org/10.1093/bja/aeq302

[8] Flick RP, Katusic SK, Colligan RC, et al. Cognitive and behavioral outcomes after early exposure to anesthesia and surgery. Pediatrics 2011; 128: e1053-61. http://dx.doi.org/10.1542/peds.2011-0351

[9] Gastroesophageal reflux in infants. National Institute of Diabetes and Digestive and Kidney Diseases. http://digestive.niddk.nih.gov/ddiseases/pubs/gerdinfant/gerdi nfant/

[10] Winter HS. Gastroesophageal reflux in infants. www.uptodate.com/index. Accessed Oct. 10, 2012.

[11] Full-term infants: Issues to consider: Reflux. Pediatric Nutrition Care Manual. Academy of Nutrition and Dietetics. http://nutritioncaremanual.org/index.cfm. Accessed March 11, 2013.

[12] Schurr P, Findlater CK. Neonatal mythbusters: Evaluating the evidence for and against pharmacologic and nonpharmacologic management of gastroesophageal reflux.

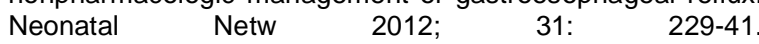
http://www.ncbi.nlm.nih.gov/pubmed/22763250

[13] Kotlow L. Oral diagnosis of abnormal frenum attachments in neonates and infants: evaluation and treatment of the maxillary and lingual frenum using the Erbium: YAG laser. $J$ Ped Dental Care 2004a; 10: 11-4.

[14] Kotlow L. Oral diagnosis of abnormal frenum attachments in neonates and infants. J Ped Dental Care 2004b; 10: 26-8.

[15] Kotlow L. Diagnosis and treatment of ankyloglossia and tied maxillary fraenum in infants using Er:YAG and 1064 diode lasers. Eur Arch Paediatr Dent 2011; 12: 106-12. http://dx.doi.org/10.1007/BF03262789

[16] Kotlow L. Diagnosing and understanding the maxillary lip-tie (superior labial, the maxillary labial frenum) as it relates to breastfeeding. J Hum Lact 2013; 29: 458-64. http://dx.doi.org/10.1177/0890334413491325

[17] Martinelli RL, Marchesan IQ, Berretin-Felix G. Lingual frenulum protocol with scores for infants. Int $\mathrm{J}$ Orofacial Myology 2012; 38: 104-12.

[18] O'Callahan C, Macary S, Clemente S. The effects of officebased frenotomy for anterior and posterior ankyloglossia on breastfeeding. Int J Pediatr Otorhinolaryngol 2013; 77: 82732.

http://dx.doi.org/10.1016/j.ijporl.2013.02.022

[19] Buryk M, Bloom D, Shope T. Efficacy of neonatal release of ankyloglossia: a randomized trial. Pediatrics 2011; 128: 280. http://dx.doi.org/10.1542/peds.2011-0077

(c) 2016 Lawrence Kotlow; Licensee Lifescience Global.

This is an open access article licensed under the terms of the Creative Commons Attribution Non-Commercial License (http://creativecommons.org/licenses/by-nc/3.0/) which permits unrestricted, non-commercial use, distribution and reproduction in any medium, provided the work is properly cited. 